\title{
Terpenes Functionalization: A Comparative Study in Catalytic Activity of Mesoporous Materials Modified with Ti and V
}

\author{
Analía L. Cánepa ${ }^{1,2,}{ }^{*}$, Luis E. Aguirre ${ }^{1}$, Eduardo R. Herrero ${ }^{1}$, Griselda A. Eimer ${ }^{1,2}$ and Sandra G. \\ Casuscelli $1^{1,2}$
}

${ }^{I}$ Centro de Investigación y Tecnología Química (CITeQ) / Universidad Tecnológica Nacional, Facultad Regional Córdoba, Maestro López esq. Cruz Roja Argentina, S/N, X5016ZAA, Córdoba, Argentina

${ }^{2}$ Consejo Nacional de Investigaciones Cientificas y Técnicas (CONICET), Av. Rivadavia 1917, C1033AAJ, Buenos Aires, Argentina

\begin{abstract}
The catalytic performance of mesoporous materials with a MCM-41 structure in the reaction of $\alpha$-pinene oxidation with $\mathrm{H}_{2} \mathrm{O}_{2}$ was investigated by a comparative study of Ti-MCM-41 and V-MCM-41 catalysts. These materials were prepared by hydrothermal synthesis, from theoretical molar ratios silicon / metal $(\mathrm{Si} / \mathrm{M})=20,60$ and 240 in the initial synthesis gel. The results of the catalytic evaluation showed that for a similar molar content of metal in the materials ( 0.023 mole of metal $/ 100 \mathrm{~g}$ of catalyst), Ti-MCM-41 presented the best TON values. Moreover, V-MCM-41 showed a lower efficiency of $\mathrm{H}_{2} \mathrm{O}_{2}$ than Ti-MCM-41, which can be attributed to the presence of clusters species $(\mathrm{V}-\mathrm{O}-\mathrm{V})_{\mathrm{n}}$ and nanooxides $\mathrm{V}_{\mathrm{x}} \mathrm{O}_{\mathrm{y}}$ which accelerate the decomposition reaction of peroxide to water. On the other hand, it is noteworthy that the polymerization degree of the surface vanadium species and the appearance of $\mathrm{V}_{\mathrm{x}} \mathrm{O}_{\mathrm{y}}$ crystallites have a significant effect on the selectivity to the products obtained.
\end{abstract}

Keywords: Mesoporous materials, $\alpha$-pinene, Oxidation, Ti-MCM-41, V-MCM-41.

\section{INTRODUCTION}

The homogeneous oxidation reactions in the liquid phase generally employ soluble metal salts or complexes in combination with different oxidants. However, the use of these catalysts has the disadvantage that its active species tend to dimerize/oligomerize to less reactive oxo species [1]. Thus, isolating the active species on solid inorganic matrices is a very effective way to resolve this problem. Various strategies can be employed for immobilizing active elements in a solid (inorganic) matrix [2]. Metal ions can be isomorphously substituted in framework positions of molecular sieves via hydrothermal synthesis or post synthesis modification such as impregnation and ion exchange [1-3]. It is known that the use of hydrothermal synthesis results in greater incorporation of the active species than using the impregnation technique [4]. Particularly, the M41S family of mesoporous materials has acquired great importance due to the possibility of adapting their catalytic properties such as type and force of acid and/or basic sites, hydrophilicity/hydrophobicity, structure and size of pores [5]. Since $90 \mathrm{~s}$ the trend has been to modify MCM-41 structures with several transitional metals such as $\mathrm{Ti}, \mathrm{V}$ or $\mathrm{Nb}$ with the aim to prepare catalyst with redox properties, to be applied in fine chemistry reaction $[6,7]$. Thus, Ti-MCM-41 and V-MCM41 , are widely studied because of their potential catalytic

*Address correspondence to this author at the Centro de Investigación y Tecnología Química (CITeQ) / Universidad Tecnológica Nacional, Facultad Regional Córdoba, Maestro López esq. Cruz Roja Argentina, S/N, X5016ZAA, Córdoba, Argentina; Tel/Fax: 54-351-4690585;

E-mail:acanepa@scdt.frc.utn.edu.ar properties in the olefin and alcohol selective oxidations. Parvulescu et al. reported the oxidation of different hydrocarbons such as styrene, benzene, cyclohexanol with $\mathrm{H}_{2} \mathrm{O}_{2}$ under mild conditions using MCM-41 catalyst modified with V [8]. Shylesh et al. studied the cyclooctene oxidation obtaining conversions above $30 \%$ with molar ratio $\mathrm{Si} / \mathrm{V}: 25$ and substrate/ $\mathrm{H}_{2} \mathrm{O}_{2}: 4 / 1$ after $12 \mathrm{~h}$ of reaction [9]. Meanwhile, the organic compounds oxidation and especially olefinic compounds over Ti-based catalysts using $\mathrm{H}_{2} \mathrm{O}_{2}$ as oxidizing agent, have gained considerable interest [2, 10-12]. Among the functionalization reactions of cyclic olefins, the terpenes oxidation is of industrial importance due to the possibility of transforming cheap and readily available substrate, such as $\alpha$-pinene, to valuable intermediates for chemical synthesis. Furthermore, oxygenated derivatives are used as the starting product for the synthesis of fragrances, flavours and therapeutics agent. The $\alpha$-pinene gives valuable oxygenated products, such as campholenic aldehyde (2), verbenol (5) and verbenone (6) (Fig. 1). The campholenic aldehyde is an important intermediate for the synthesis of santalol, the main constituent of natural sandalwood oil [13-15], while verbenol and verbenone are used as intermediate for the pesticides manufacture and the flavoring industry [16-18]. Among the oxidation products of $\alpha$-pinene, verbenone is of great interest as it can provide a possible starting point for the synthesis of taxol, an important therapeutic agent [13, 19-21].

In this work, the catalytic performance of mesoporous materials with a MCM-41 structure in the reaction of $\alpha$ pinene oxidation with $\mathrm{H}_{2} \mathrm{O}_{2}$ was investigated by a comparative study of Ti-MCM-41 and V-MCM-41 catalysts, prepared by hydrothermal synthesis [22, 23]. Special attention was 


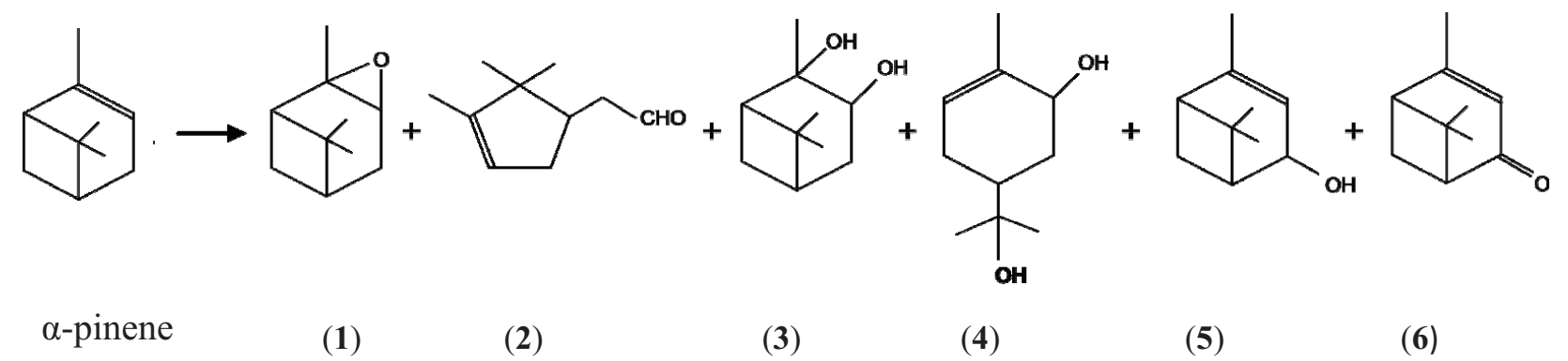

Fig. (1). Products obtained from $\alpha$-pinene oxidation. $\alpha$-Pinene oxide (1), campholenic aldehyde (2), 1,2 pinanediol (3), trans-sobrerol (4), verbenol (5), verbenone (6).

Table 1. Chemical Composition of MCM-41 Modified with Ti and V.

\begin{tabular}{|c|c|c|c|}
\hline \multirow{2}{*}{$\begin{array}{c}\text { Metal Content } \\
\text { (wt. \%) }^{\mathbf{a}}\end{array}$} & $\mathbf{2 4 0}$ & $\mathbf{6 0}$ & \multicolumn{3}{|c|}{ Si/M $^{\mathbf{b}}$} \\
\cline { 2 - 5 } & 0.240 & 1.120 & $\mathbf{2 0}$ \\
\hline \hline $\mathrm{Ti}$ & 0.035 & 0.140 & 2.500 \\
\hline $\mathrm{V}$ & & 1.210 \\
\hline
\end{tabular}

a In the final solid

${ }^{\mathrm{b}}$ Molar ratio in the initial synthesis gel

paid on the correlation between the structural properties of the materials obtained with their catalytic activity.

\section{MATERIALS AND METHODS}

\section{Catalyst Synthesis and Characterization Techniques}

Ti-MCM-41 and V-MCM-41 evaluated in this work were prepared by hydrothermal synthesis using cetyltrimethyl ammonium bromide (CTABr) as template and tetraethoxysilane (TEOS) as Si source and Ti (IV) isopropoxide (Fluka, $98 \%$ ) and $\mathrm{VO}\left(\mathrm{SO}_{4}\right) \cdot \mathrm{H}_{2} \mathrm{O}$ (Aldrich, 99,99\%) as $\mathrm{Ti}$ and $\mathrm{V}$ source respectively $[22,23]$. The $\mathrm{pH}$ of the synthesis was adjusted to 13 by adding of a tetra ethyl ammonium hydroxide $(\mathrm{TEAOH}) 20 \mathrm{wt} \%$ aqueous solutions. Precursors were mixed and maintained under stirring during $3 \mathrm{~h}$; afterwards the resulting gel was heated at $100{ }^{\circ} \mathrm{C}$ in a Teflon-lined autoclave under autogenic pressure for a given time [23, 24]. The catalysts were synthesized from molar ratios of silicon/metal $(\mathrm{Si} / \mathrm{M}): 20,60$, and 240 . The solid obtained was filtered, washed with distilled water and dried overnight at $60{ }^{\circ} \mathrm{C}$. The template agent was evacuated from the samples by heating $\left(2{ }^{\circ} \mathrm{C} / \mathrm{min}\right)$ under $\mathrm{N}_{2}$ flow $(45 \mathrm{~mL} / \mathrm{min})$ at $773 \mathrm{~K}$ for $6 \mathrm{~h}$ and subsequent calcination at $500{ }^{\circ} \mathrm{C}$ for $6 \mathrm{~h}$ under dry air flow $(45 \mathrm{~mL} / \mathrm{min})$.

The characterization of the materials evaluated in this work was previously reported [22-24]. Here, we mention only those aspects which are most relevant to compare the materials studied.

\section{$\alpha$-Pinene Oxidation}

The chemical reactions were carried out in a glass reactor with a magnetic stirrer, immersed in a thermally controlled bath at $70^{\circ} \mathrm{C}$. Typically, the reaction mixture consisted of $6.14 \mathrm{mmol}$ of $\alpha$-pinene, $1.54 \mathrm{mmol}$ of $\mathrm{H}_{2} \mathrm{O}_{2} 35 \%, 92.19$ mmol of acetonitrile and $54 \mathrm{mg}$ of catalyst. Reaction pro- gress was followed taking samples during reaction through sealed septa by means of a syringe. Liquid samples were filtered and analyzed by gas chromatography using a capillary column (crosslinked methyl-silicone gum) connected to a FID detector. Reaction products were identified by mass spectrometry in a Shimadzu GCMS-QP 5050 with HP-5 capillary column. The $\alpha$-pinene conversion was defined as the ratio of converted species to initial concentration and the selectivity as (mol product/mol total products) $x 100$. The turnover number (TON) was defined as moles of olefin converted $/ \mathrm{mol}$ of metal in the catalyst. Finally, the total conversion of $\mathrm{H}_{2} \mathrm{O}_{2}$ was measured by iodometric titration and $\mathrm{H}_{2} \mathrm{O}_{2}$ efficiency was calculated as the percentage of this reactive converted to total oxidized products.

\section{RESULTS AND DISCUSSION}

Table 1 summarizes the chemical composition of mesoporous materials modified with $\mathrm{Ti}$ and $\mathrm{V}$ selected for this study. The metal content in each catalyst was determined by inductively coupled plasma optical emission spectroscopy (ICP-OES) after the digestion of the samples. As it can be seen, although the molar ratios of silicon/metal $(\mathrm{Si} / \mathrm{M})$ used in the initial synthesis gel for both metals were the same, the content of $\mathrm{Ti}$ in the final solid was considerably higher than the content of $\mathrm{V}$ for the three relationships studied. The reason why the material incorporates different amounts of metal, remains unclear. A possible explanation to understand this behavior could be considering the different hydrolysis reaction rate for each metal precursor, taking into account also the nature of the sources used, (alkoxide of the $\mathrm{Ti}$ and inorganic salt of V) $[25,26]$. Hence, many kinds of metals can be hydrolyzed with ease and be transformed to metal oxide via a condensation-polymerization reaction. It is known that the reaction rates of hydrolysis of transition metals depend on the electron affinities, sizes, charges and coordination numbers of metal ions [27-29]. 

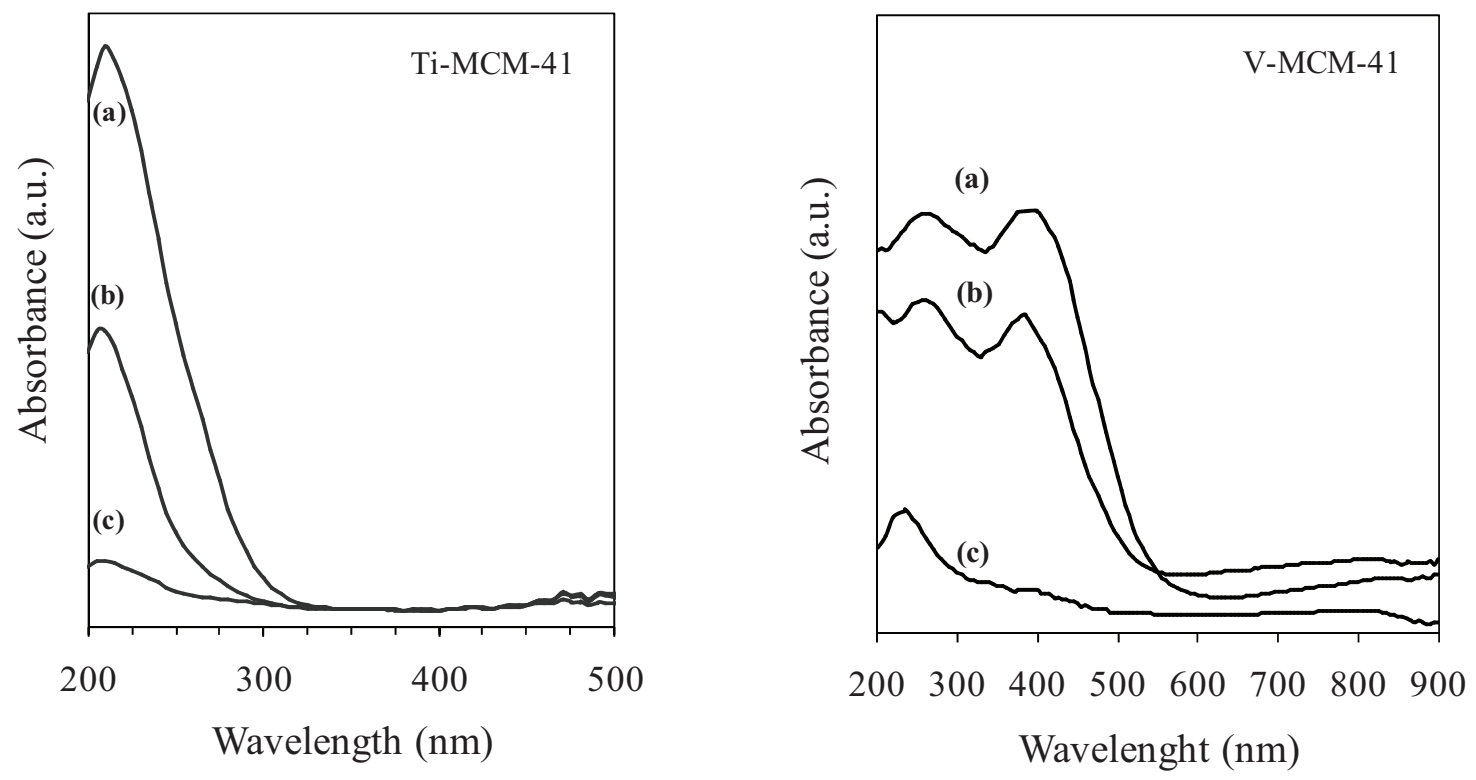

Fig. (2). UV-vis diffuse reflectance spectra of the calcined Ti-MCM-41 and V-MCM-41 catalysts. Si/M: (a) 20, (b) 60, (c) 240.

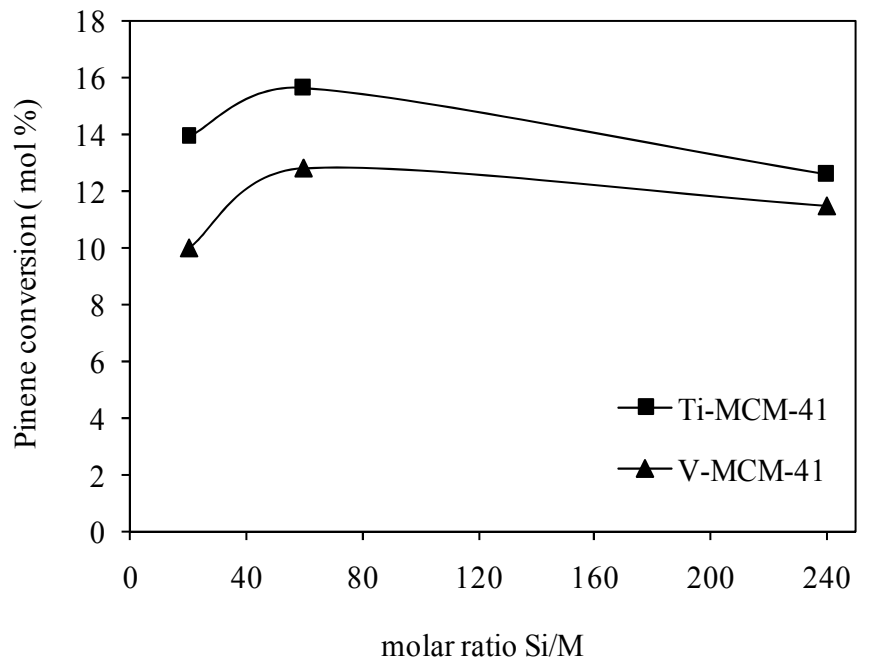

Fig. (3). $\alpha$-Pinene conversion for reaction with Ti-MCM-41 and V-MCM-41. Reaction conditions: molar ratio substrate/oxidant: 4/1, temperature: $70^{\circ} \mathrm{C}$, catalyst: $9 \mathrm{mg} / \mathrm{mL}$, reaction time $7 \mathrm{~h}$.

The Diffuse reflectance UV-visible (UV-Vis-DR) spectra of Ti-MCM-41 samples (Fig. 2) showed an intense band at $210 \mathrm{~nm}$ in all the samples indicating that most of the Ti species are isolated and in tetrahedral coordination inside the framework. Moreover, the intensity of the $210 \mathrm{~nm}$ band is substantially increased and the position of the maximum does not shift towards higher wavelengths with increasing $\mathrm{Ti}$ content. Such behavior suggests that the tetrahedral component of Ti (IV) prevails even in the samples synthesized with high Ti content. A shoulder at $250-270 \mathrm{~nm}$ becomes significant in the samples with relatively high Ti content, which can be attributed to the presence of some $(\mathrm{Ti}-\mathrm{O}-\mathrm{Ti})_{\mathrm{n}}$ clusters in the framework due to an incipient oligomerization of $\mathrm{Ti}$ species [21-22]. Furthermore, the presence of higher coordination Ti species probably due to the insertion of water molecules upon hydration cannot be unequivocally excluded [22].
The absorption band around $260 \mathrm{~nm}$ in the spectra for the sieve modified with $\mathrm{V}$ indicates that of $\mathrm{V}$ ions are isolated and in tetrahedral coordination possibly with the lattice oxygen (Fig. 2). A second band at $370 \mathrm{~nm}$, which is in the samples $\mathrm{Si} / \mathrm{V}=60$ and 20 , can be attributed to the presence of some $(\mathrm{V}-\mathrm{O}-\mathrm{V})_{\mathrm{n}}$ clusters due to an incipient oligomerization of $\mathrm{V}$ species and/or to a higher coordination of $\mathrm{V}$ ions [23]. Finally, a new band around $450 \mathrm{~nm}$ only appears for the higher $\mathrm{V}$ content catalyst. This band could be attributed to $\mathrm{V}$ ions in the octahedral symmetry in $\mathrm{V}_{\mathrm{x}} \mathrm{O}_{\mathrm{y}}$ crystallites. These nano-oxides can possibly be generated as consequence of a further polymerization degree of the $\mathrm{V}$ species due to the high content of $\mathrm{V}$ in the initial synthesis gel.

Ti-MCM-41 and V-MCM-41 catalysts were tested in the reaction of $\alpha$-pinene oxidation with $\mathrm{H}_{2} \mathrm{O}_{2}$ at $70^{\circ} \mathrm{C}$. Fig. (3) shows the effect of the molar ratio variation $\mathrm{Si} / \mathrm{M}$ in the initial synthesis gel on the oxidation of $\alpha$-pinene. The general 


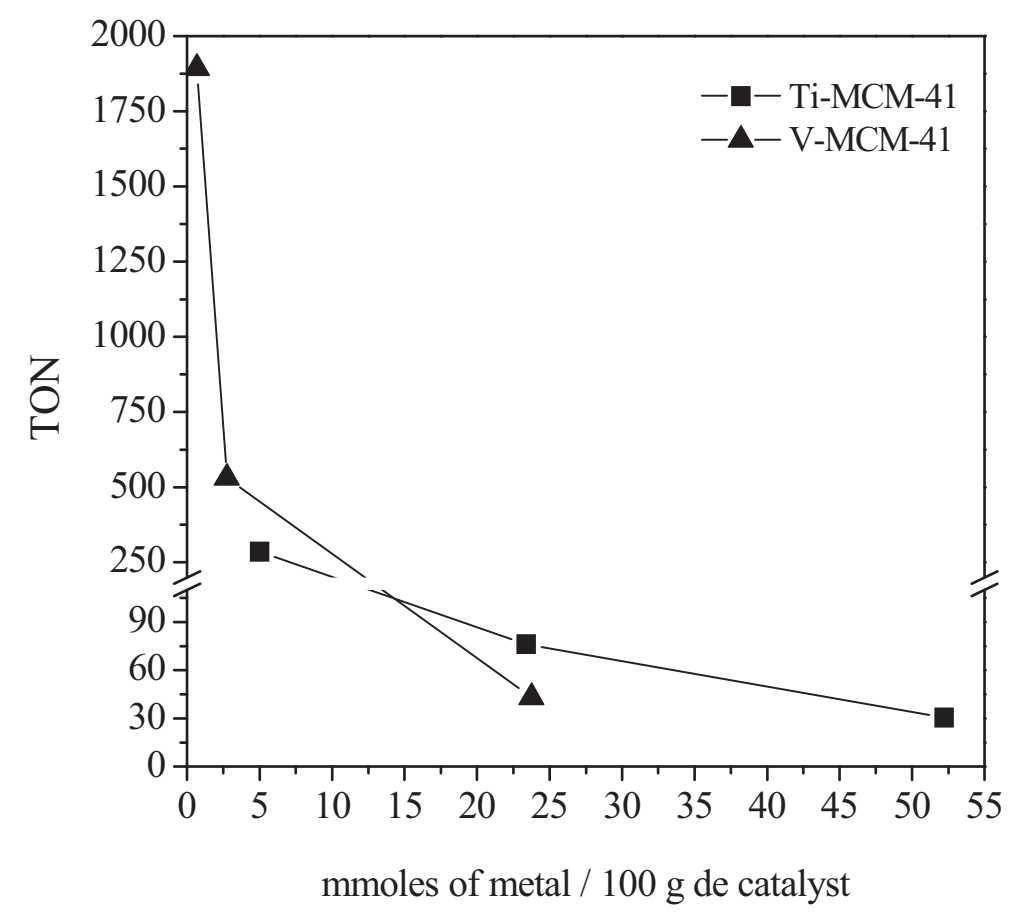

Fig. (4). TON values as a function of the metal moles in the final solid. Reaction conditions: molar ratio substrate/oxidant: 4/1, temperature: $70{ }^{\circ} \mathrm{C}$, catalyst: $9 \mathrm{mg} / \mathrm{mL}$, reaction time $7 \mathrm{~h}$.

Table 2. Conversion and Efficiency of $\mathrm{H}_{2} \mathrm{O}_{2}$

\begin{tabular}{|c|c|c|c|c|}
\hline Si/M & wt. \% & Metal Molar Loading* & $\begin{array}{c}\mathbf{H}_{2} \mathbf{O}_{2} \text { Conversion } \\
\text { (mol \%) }\end{array}$ & $\begin{array}{c}\mathbf{H}_{2} \mathbf{O}_{2} \text { Efficiency } \\
\text { (mol \%) }\end{array}$ \\
\hline \hline $\mathrm{Ti}$ & 1.120 & 0.023 & 81.46 & 75.66 \\
\hline $\mathrm{V}$ & 1.210 & 0.023 & 91.26 & 38.34 \\
\hline
\end{tabular}

*moles metal $/ 100$ g catalyst

trend is that Ti-modified materials showed a slightly higher activity than that of $\mathrm{V}$; however, this increase was not the expected considering the total amount of metal in the final solid. Besides, as it can be seen, for the metal content increasing, $(\mathrm{Si} / \mathrm{M} 240$ to 60$)$, the $\alpha$-pinene conversion increased for both materials. These results could be interpreted taking into account the higher proportion of isolated $\mathrm{Ti}$ and $\mathrm{V}$ ions in tetrahedral coordination in the samples of molar ratio 240 and 60, which would be the active species in the $\alpha$ pinene oxidation $[12,23]$. Meanwhile, for materials with high metal loading, $\mathrm{Si} / \mathrm{M}=20$, the lowest activity can be associated to the incipient oligomerization of $\mathrm{Ti}$ species forming small clusters. In the case of $\mathrm{V}$ this behavior can be related to an incipient oligomerization of $\mathrm{V}$ species and the $\mathrm{V}_{\mathrm{x}} \mathrm{O}_{\mathrm{y}}$ nano particles observed, as it was already mentioned, by UV-Vis-DR. These nanoparticles could be located inside the material channels, as well as on the external surface, thus diminishing or blocking the accessibility to the active sites (isolated $\mathrm{V}$ ions), which causes a decrease of the catalytic activity [22, 23].

On the other hand, according to literature, the intrinsic catalytic activity of different catalysts can better be compared using the turnover number (TON), defined as moles converted per active site [30]. Thus, in the Fig. (4) TON values are presented for the materials $\mathrm{Ti}$ and $\mathrm{V}$ with respect to the metal molar loading, which is defined as moles of metal/100 g of catalyst. In this way, for a content of 0.023 moles of metal ( $\mathrm{Ti}$ or $\mathrm{V}) / 100 \mathrm{~g}$ of catalyst, the material modified with Ti showed better catalytic performance. The activity differences of the two catalysts could be attributed to the redox nature of the two $3 \mathrm{~d}$ transition metals ( $\mathrm{Ti}$ and $\mathrm{V}$ ), since it is known that the lower the density of the outer delectron, the stronger the capacity to activate the $\mathrm{H}_{2} \mathrm{O}_{2}$ as was observed in the Ti-MCM-41 [31].

Moreover, to complete the analysis we must consider the parallel reaction of decomposition of peroxide to water. Table 2 lists the $\mathrm{H}_{2} \mathrm{O}_{2}$ conversion data for Ti-MCM-41 and VMCM-41 with the same metal molar loading. Thus, taking into account that the distribution of metallic species determined by UV-vis-DR are different for Ti and V-MCM-41, the lowest efficiency of $\mathrm{H}_{2} \mathrm{O}_{2}$ observed with the mesoporous material modified with $\mathrm{V}$ probably derives from the formation of highly coordinated vanadium species. These species, present as clusters and nano oxides, would be responsible for the parallel reaction of peroxide decomposition in water decreasing the efficiency. 


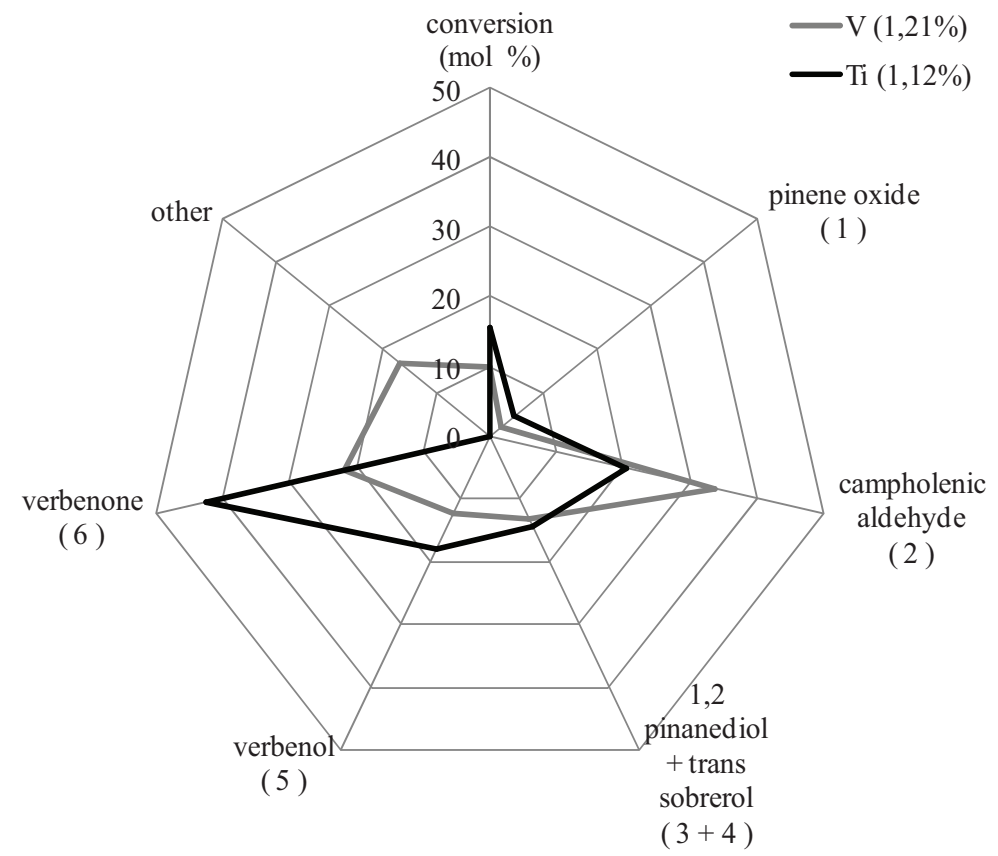

Fig. (5). Products selectivity for the $\alpha$-pinene oxidation over Ti-MCM-41 (1.120\%) and V-MCM-41 (1.210\%).

Finally, Fig. (5) shows the different products observed for $7 \mathrm{~h}$ reaction for Ti-MCM-41 and V-MCM-41 catalysts. According to GC-MS analyses, the products mixture is composed of species formed by oxidation of both double bond (1, 2, 3 and 4$)$ and allylic $\mathrm{C}-\mathrm{H}$ bond (5 and $\mathbf{6})$, being verbenone and campholenic aldehyde the major products for the Ti-MCM-41 and V-MCM-41 respectively. Furthermore, with V-MCM-41 were obtained over-oxidation products which were named as other. This behavior would be giving account that the vanadium surface density is a quite important parameter that affects the selectivity of the reaction of $\alpha$ pinene oxidation. Thus, the polymerization degree of the surface vanadium species and the appearance of $\mathrm{V}_{\mathrm{x}} \mathrm{O}_{\mathrm{y}}$ crystallites have a significant effect on the selectivity to the products obtained. Probably, the $\alpha$-pinene may react over two $\mathrm{V}$ atoms of $(\mathrm{V}-\mathrm{O}-\mathrm{V})_{\mathrm{n}}$ species favoring the consecutive reactions of over-oxidation and decreasing the selectivity to interest products [32].

\section{CONCLUSIONS}

Mesoporous materials modified with $\mathrm{Ti}$ and $\mathrm{V}$ were synthesized from theoretical molar ratios Si/M: 20, 60 and 240 in the starting gel, yielding greater incorporation of metal for the Ti series. All tested materials were active in the $\alpha$-pinene functionalization with $\mathrm{H}_{2} \mathrm{O}_{2}$. The intrinsic catalytic activity of the synthesized catalysts was compared using the turnover number (TON) with respect to the metal molar loading. Thus, for a content of $1.120 \mathrm{wt}$. \% Ti and $1.210 \mathrm{wt} . \% \mathrm{~V}$ that is 0.023 mole of metal (Ti or V)/100 g of catalyst, a better performance of catalytic activity was achieved on the $\mathrm{Ti}$ modified material.

On the other hand, the $\mathrm{V}$ catalyst showed a lower $\mathrm{H}_{2} \mathrm{O}_{2}$ efficiency, which could be attributed to the formation of highly coordinated vanadium species, present as clusters and nano oxides determined by UV-Vis-RD. Thus, the presence of these species could accelerate the decomposition reaction of peroxide to water reducing its catalytic performance.

Regarding the distribution of products verbenone and campholenic aldehyde were obtained as the major products for the Ti-MCM-41 and V-MCM-41 respectively. Furthermore, with V-MCM-41 were obtained over-oxidation products. This behavior would give account that the polymerization degree of the surface vanadium species and the appearance of $\mathrm{V}_{\mathrm{x}} \mathrm{O}_{\mathrm{y}}$ crystallites could promote the consecutive reactions of over-oxidation and decreasing the selectivity to interest products.

\section{CONFLICT OF INTEREST}

The authors confirm that this article content has no conflicts of interest.

\section{ACKNOWLEDGEMENTS}

The authors would like to thank CONICET and UTN FRC for their financial support and scholarships. A.L.C thank to M. Ponte and N. Waisman for their assistance in experimental development.

\section{REFERENCES}

[1] Arends, I.W.C.E.; Sheldon, R.A. Activities and stabilities of heterogeneous catalysts in selective liquid phase oxidations: recent developments. Appl. Catal. A, 2001, 212, 175-187.

[2] Arends, I.W.C.E.; Sheldon, R.A.; Wallau, M.; Schuchardt, U. Oxidative Transformations of Organic Compounds Mediated by Redox Molecular Sieves. Angew. Chem. Int. Ed. Engl., 1997, 36, 11441163.

[3] Schneider, M.; Baiker, A. Aerogels in Catalysis. Catal. Rev. Sci. Eng., 1995, 37, 515-556.

[4] Brunel, D. Functionalized micelle-templated silicas (MTS) and their use as catalysts for fine chemicals. Microporous Mesoporous Mater., 1999, 27, 329-344. 
[5] Corma, A. From Microporous to mesoporous molecular sieve materials and their use in catalysis Chem. Rev., 1997, 97, 2373-2419.

[6] Decyk, P.; Trejda M.; Ziolek M.; Lewandowska, A. Characterization of iron containing molecular sieves the effect of T-element on Fe species. Stud. Surf. Sci. Catal., 2002, 142, 1785-1792.

[7] Gontier, S.; Tuel, A. Characterization of vanadium-containing mesoporous silicas. Microporous Mater., 1995, 5, 161-171.

[8] Parvulescu, V.; Anastasescu, C.; Su, B.L. Vanadium incorporated mesoporous silicates as catalysts for oxidation of alcohols and aromatics. J. Molec. Catal. A, 2003, 198, 249-261.

[9] Shylesh, S.; Singh, A.P. Vanadium-containing ordered mesoporous silicates: Does the silica source really affect the catalytic activity, structural stability, and nature of vanadium sites in V-MCM-41? J. Cat., 2005, 233, 359-371.

[10] Notari, B. Microporous Crystalline Titanium Silicates. Adv. Catal., 1996, 41, 253-334.

[11] Van der Waal, J.; Rigutto, M.; Van Bekkum, H. Zeolite titanium beta as a selective catalyst in the epoxidation of bulky alkenes. Appl. Catal. A, 1998, 167, 331-342.

[12] Casuscelli, S.G.; Eimer, G.A.; Cánepa, A.L.; Heredia, A.C.; Poncio, C.A.; Crivello, M.E.; Perez, C.F.; Aguilar, A.; Herrero, E.R. Ti-MCM-41 as catalyst for $\alpha$-pinene oxidation. Study of the effect of Ti content and $\mathrm{H}_{2} \mathrm{O}_{2}$ addition on activity and selectivity. Catal. Today, 2008, 133, 678-683.

[13] Murphy, E.F.; Mallat, T.; Baiker, A. Allylic oxofunctionalization of cyclic olefins with homogeneous and heterogeneous catalysts. Catal. Today, 2000, 57, 115-126.

[14] Albert, R.M.; Traynor, S.G.; Webb, R.L. Fragrance and flavor chemicals, Pulp Chemicals Association, New York, 1989.

[15] Orloff, G.; Winter, B.; Fehr en Perfumes, C.; Art, Sciences and Technology, Elsevier, New York, 1991.

[16] Sivik, M.R.; Stanton, K.J.; Paquette, L.A. (1R,5R)-(+)-Verbenone of high optical purity.Org. Synth., 1995, 72, 57-61.

[17] Passaro, L.C.; Webster, F.X. Synthesis of the Female Sex Pheromone of the Citrus Mealybug, Planococcuscitri. J. Agric. Food. Chem., 2004, 52 (10), 2896-2899.

[18] Simakova, I.L.; Semikolenov, V.A. The catalytic method of verbenol preparation with controlled isomer distribution starting from renewable material $\alpha$-pinene. Chem. Sust. Dev., 2003, 11, 271-275.

[19] Wender, P.A.; Mucciaro, T.P. A new and practical approach to the synthesis of taxol and taxol analogs: the pinene path. J. Am. Chem. Soc., 1992, 114, 5878-5879.
[20] Winkler, J.D.; Bhattacharya, S.K.; Liotta, F.; Batey, R.A.; Heffernan, G.D.; Cladingboel, D.E.; Kelly, R.C. Stereoselective synthesis of a synthon for the A-ring of taxol from R-(+)-verbenone. Tetrahedron Lett., 1995, 36 (13), 2211-2214.

[21] Trissa, J.; Sawant, D.P.; Gopinath, C.S.; Halligudi, S.B. Zeolite encapsulated ruthenium and cobalt schiff base complexes catalyzed allylic oxidation of $\alpha$-pinene. J. Mol. Catal. A., 2002, 184 (1-2), 289-299.

[22] Eimer, G.; Casuscelli, S.; Ghione, G.; Crivello, M.; Herrero, E. Synthesis, characterization and selective oxidation properties of Ticontaining mesoporous catalysts. Appl. Catal. A: General, 2006, 298, 232-242.

[23] Chanquía, C.M.; Cánepa, A.L.; Sapag, K.; Reyes, P.; Herrero, E.R. ;Casuscelli, S.G.; Eimer, G.A. Mesoporous silicates with spherical morphology modified with vanadium highly active in oxidation of cyclohexene with $\mathrm{H}_{2} \mathrm{O}_{2}$. Top. Catal., 2011, 54, 160-169.

[24] Eimer, G.A.; Chanquía, C.M.; Sapag, K.; Herrero, E. R. The role of different parameters of synthesis in the final structure of $\mathrm{Ti}$ containing mesoporous materials. Micro. Mesoporous Mater. ,2008, 116 670-676.

[25] Rojas, Cervantes, M. L., Diseño y síntesis de materiales " a medida" mediante el método sol-gel. 1st. ed; UNED: Madrid, 2012.

[26] Cabrera, S.; Haskouri, J.; Guillem, C.; Latorre, J.; Beltrán-Porter, A.; Beltrán-Porter, D.; Marcos, M.; Amorós, P. Generalised syntheses of ordered mesoporous oxides: the atrane route. Solid State Sci., 2000, 2, 405-420.

[27] Livage, J. Chemical Processing of Ceramics; Marcel Dekker Inc.: New York, 1994.

[28] Brinker, C. J.; Scherer, G. W. Sol-Gel Science; Academic Press: New York, 1990.

[29] Livage, J.; Henry, M.; Sanchez, C. Sol-gel chemistry of transition metal oxides. Prog. Solid State Chem., 1988, 18, 259-341.

[30] Thomas, J.M.; Thomas; W.J. Principles of Heterogeneous Catalysis, VCH, New York, 1997.

[31] Shylesh, S.; Singh, A.P. Synthesis, characterization and catalytic activity of vanadium-incorporated, -grafted, and -immobilized mesoporous MCM-41 in the oxidation of aromatics. J. Catal., 2004, 228, 333-346.

[32] Liu, Y.M.; Cao, Y.; Yi, N.; Feng, W.L.; Dai, W.L.; Yan, S.R.; He, H.Y.; Fan, K.N. Vanadium oxide supported on mesoporous SBA15 as highly selective catalysts in the oxidative dehydrogenation of propane. J. Catal., 2004, 224, 417-428. 